\title{
FAKTOR-FAKTOR YANG MEMPENGARUHI PERMUKIMAN KUMUH DI KOTA BUKITTINGGI
}

\author{
Wilko Rahmad Zulkarnaini ${ }^{1)}$ \\ Elfindri ${ }^{2}$ \\ Delfia Tanjung Sari ${ }^{3)}$ \\ Magister Fakultas Ekonomi Universitas Andalas Padang ${ }^{1}$ \\ Fakultas Ekonomi Universitas Andalas Padang ${ }^{2,3}$ \\ Penulis Korespondensi e-mail :wilko_rahmat@yahoo.com
}

\begin{abstract}
Cities are spatial plans on the surface (land) with administrative boundaries that have been determined where there is concentration of the population in it along with various economic, social and political activities. The city is a residential spatial structure with a large number of people on limited urban land, which is generally non-agrarian. The development of the city does not always have a positive impact, but it has a negative impact including the emergence of slum areas around the city center. Around the city center there are various centers of activity including tourism, health, education and trade as well as services in the city, provincial and national levels. The five activities are developing quite rapidly which has resulted in the development of residential areas around the city center and the poor development of slums in these locationsThe purpose of this study is to analyze the factors that influence the development of slums. The research location is in the city of Bukittinggi, West Sumatra Province. This study uses primary data by distributing questionnaires to households throughout the City of Bukittinggi. The analysis used is logistic regression analysis. The results showed the factors that influence the development of slums including the Quality of Dwelling, Building Density, Education and Road Accessibility. These influencing factors can be used as a reference for alleviating slums in Bukittinggi City.
\end{abstract}

Keywords: cities, households, slum areas.

\begin{abstract}
ABSTRAK
Kota merupakan suatu tempat pemusatan berbagai kegiatan manusia baik dari kegiatan sosial, kegiatan ekonomi, maupun kegiatan politik dimana berkonsentrasi pada satu tata ruang di atas permuakaan (darat) yang memiliki batas-batas wilayah administrasi yang sudah ditetapkan. Kota merupakan suatu tata ruang permukiman berpenduduk dengan jumlah yang banyak di atas lahan perkotaan yang terbatas, yang pada umumnya bersifat non agraris. Perkembangan kota tidak selalu menimbulkan dampak positif, namun memiliki dampak negatif diantaranya munculnya kawasan permukiman kumuh di sekitar pusat kota. Di sekitar pusat kota memiliki berbagai pusat kegiatan diantaranya pariwisata, kesehatan, pendidikan dan perdagangan serta jasa baik di lingkup kota, provinsi maupun nasional. Kelima kegiatan tersebut berkembang dengan cukup pesat yang mengakibatkan berkembang kawasan permukiman di sekitar pusat kota dan buruknya berkembang permukiman kumuh di lokasi tersebut. Tujuan dari penelitian ini adalah untuk menganalisis faktor-faktor yang mempengaruhi perkembangan permukiman kumuh. Lokasi penelitian berada di Kota Bukittinggi Provinsi Sumatera Barat. Penelitian ini menggunakan data primer dengan menyebarkan kuesioner ke rumah tangga se-Kota Bukittinggi. Analisis yang digunakan adalah analisis regresi logistik. Hasil penelitian menunjukkan faktor-faktor yang mempengaruhi perkembangan permukiman kumuh diantaranya Kualitas Hunian, Kepadatan Bangunan, Pendidikan dan Aksesibilitas Jalan. Faktor-faktor yang mempengaruhi ini dapat dijadikan sebagai acuan guna pengentasan permukiman kumuh di Kota Bukittinggi. Kata kunci: kota, rumah tangga, permukiman kumuh.
\end{abstract}


Jurnal Planologi Vol. 16, No. 2, Oktober 2019

Available : http://jurnal.unissula.ac.id/index.php/psa

\section{PENDAHULUAN}

Persatuan Bangsa-Bangsa (PBB) sudah menetapkan target guna pengentasan permukiman kumuh dan pengentasan kemiskinan untuk di berbagai aspek kehidupan manusia di dunia sampai dengan Tahun 2030. Target tersebut disampaikan melalui Sustainable Development Goals (SDGs), salah satu diantaranya adalah menjamin akses perumahan dan pelayanan dasar yang memadai, aman dan terjangkau bagi permukiman kumuh di dunia.

Sesuai dengan amanat UU No. 1 Tahun 2011 tentang Perumahan dan Kawasan Permukiman mengamanatkan bahwa penyelenggaraan atas perumahan dan kawasan permukiman termasuk pencegahan kumuh dan peningkatan kualitas permukiman kumuh wajib dilakukan oleh pemerintah, Pemerintah Daerah, dan/atau setiap orang. Selanjutnya, Peraturan Presiden Nomor 2 tahun 2015 tentang Pembangunan Nasional yang dituangkan dalam RPJMN (rencana pembangunan jangka menengah nasional) 2015-2019, salah satu sasaran pembangunan lingkungan adalah $0 \%$ pengentasan permukiman kumuh perkotaan, dengan Program Peningkatan Kualitas Kawasan Permukiman yang meliputi 38,431 hektar dan perbaikan program swadaya masyarakat dalam 7,683 kelurahan.

Kota Bukittinggi merupakan kota terkecil ke empat di Indonesia dengan luas 25,24 $\mathrm{Km}^{2}$, merupakan daerah tujuan wisata utama di Provinsi Sumatera Barat, disamping sebagai kota pendidikan, kota pelayanan kesehatan dan kota perdagangan dan jasa serta tempat peristirahatan. Kota Bukittinggi menjadi pusat pengembangan pariwisata di Sumatera Barat karena karakteristik alam dan budayanya serta lokasinya yang strategis dan menjadi home base bagi wisatawan yang hendak mendatangi objek- objek wisata yang ada di Sumatera Barat yang jaraknya relatif dekat dan mudah dicapai dari Kota Bukittinggi. Kota Bukittinggi dijadikan sebagai tujuan wisata utama di Sumatera Barat dimana berawal dari pencanangannya sebagai Kota Wisata yang ditetapkan dalam Rencana Induk Pembangunan Pariwisata Provinsi Sumatera Barat pada 11 Maret 1984 yang hingga saat ini berkembang menjadi Daerah Tujuan Wisata Utama di Sumatera Barat.

PDRB perkapita merupakan hasil bagi antara nilai nominal PDRB dengan jumlah penduduk pertengahan pada tahun yang sama. PDRB Perkapita Kota Bukittinggi memperlihatkan peningkatan yang cukup signifikan dari tahun ke tahun, hal ini tentu disebabkan karena cukup tingginya peningkatan nilai nominal PDRB dibandingkan dengan pertumbuhan penduduk. Perkembangan PDRB Perkapita Kota Bukittinggi pada tahun 2011 sampai tahun 2015 sebagaimana dapat dilihat dalam tabel dibawah ini; 
Jurnal Planologi Vol. 16, No. 2, Oktober 2019

Tabel 1 Perkembangan PDRB Perkapita Tahun 2011 s.d. 2015Berdasarkan Dasar Harga Konstan dan atas Dasar Harga BerlakuDi Kota Bukittinggi

\begin{tabular}{|l|c|r|r|r|r|}
\hline \multicolumn{1}{|c|}{ Uraian } & \multicolumn{1}{|c|}{2011} & \multicolumn{1}{c|}{2012} & \multicolumn{1}{c|}{2013} & \multicolumn{1}{c|}{2014} & \multicolumn{1}{c|}{2015} \\
\hline $\begin{array}{l}\text { Nilai PDRB (dalam } \\
\text { juta Rp) }\end{array}$ & 4.025 .631 & 4.487 .879 & 5.023 .308 & 5.642 .931 & 6.117 .430 .75 \\
\hline $\begin{array}{l}\text { Jumlah Penduduk } \\
\text { (jiwa) }\end{array}$ & 113.547 & 114.393 & 118.260 & 120.575 & 122.621 \\
\hline $\begin{array}{l}\text { PDRB perkapita } \\
\text { (Rp/jiwa) }\end{array}$ & 35.453 .436 & 39.232 .112 & 42.476 .817 & 46.800 .061 & 49.888 .932 \\
\hline
\end{tabular}

Sumber: BDA dan PDRB Kota Bukittinggi 2011-2015

Semakin berkembangnya berbagai sektorekonomi masyarakat Kota Bukittinggi, mengakibatkan jumlah penduduk Kota Bukittinggi menunjukkan trend peningkatan tiap tahunnya dengan laju pertumbuhan sebesar 1,68 persen per tahun. Berikut tabel jumlah penduduk Kota Bukitinggi 5 (lima) tahun terakhir :

Tabel 2 Jumlah Penduduk Kota Bukittinggi Tahun 2013 s/d 2017

\begin{tabular}{|c|c|c|}
\hline No. & Tahun & Jumlah Penduduk \\
\hline 1 & 2013 & 118.260 \\
\hline 2 & 2014 & 120.491 \\
\hline 3 & 2015 & 122.621 \\
\hline 4 & 2016 & 124.715 \\
\hline 5 & 2017 & 126.804 \\
\hline
\end{tabular}

Sumber : Bukittinggi Dalam Angka Tahun 2018

Berdasarkan tabel di atas, dapat dilihat bahwa terjadinya peningkatan jumlah penduduk Kota Bukittinggi tiap tahunnya, sementara di sisi lain luas Kota Bukittinggi yang sangat kecil serta harga lahan yang selalu naik, mengakibatkan timbulnya permukiman kumuh di Kota Bukittinggi. Keberadaan permukiman kumuh tentu menimbulkan dampak negatif bagi kehidupan penghuninya maupun kehidupan di sekitarnya.Melalui Surat Keputusan Walikota Bukittinggi Nomor 188.45-300-2014 Tanggal 19 September 2014 sudah ditetapkan kawasan permukiman kumuh di Kota Bukittinggi diantaranya Kelurahan Aur Tajungkang Tengah Sawah dan Kelurahan Pakan Kurai. Kelurahan tersebut merupakan kelurahan terpadat di Kota Bukittinggi. Dengan diketahui karakteristik yang mempengaruhi perkembangan tempat bermukim Rumah Tangga di Kota Bukittinggi. Karakteristik yang mempengaruhi ini dapat dijadikan sebagai acuan guna pengentasan permukiman kumuh di Kota Bukittinggi. 
Jurnal Planologi Vol. 16, No. 2, Oktober 2019

Available : http://jurnal.unissula.ac.id/index.php/psa

\section{METODOLOGI}

\subsection{Literatur Review}

UN Habitat dalam Slum Almanac (2015) mendefinisikan permukiman kumuh sebagai permukiman informal dengan ciri perumahan semi permanent, padat, tidak memiliki akses air, sanitasi dan keamanan yang baik. Penduduk yang lahir di daerah kumuh menyebabkan standar hidup mereka tidak membaik dari waktu ke waktu. Permukiman kumuh di negara berkembang saat ini juga dianggap sebagai bentuk jebakan kemiskinan bagi mayoritas penduduk mereka (Marx, Stoker, \& Suri, 2013).

Berdasarkan UU Nomor 1 Tahun 2011 tentang Perumahan dan Kawasan Permukiman dijelaskan bahwa permukiman kumuh adalah permukiman yang tidak layak huni karena ketidakteraturan bangunan, tingkat kepadatan bangunan yang tinggi, dan kualitas bangunan serta sarana dan prasarana yang tidak memenuhi syarat, sedangkan Perumahan Kumuh merupakan perumahan yang mengalami degradasi kualitas fungsi dari suatu tempat hunian. Dengan demikian, kawasan kumuh mengindikasikan kawasan yang padat, tidak terawat, kotor, tidak teratur, dan berkurangan. Namun, UU ini juga memiliki kelemahan, yaitu aspek legalitas tanah yang tidak disebutkan. Berdasarkan pengertian di atas sehingga dapat dijabarkan beberapa ciri-ciri permukiman kumuh dan perumahan kumuh yang dilihat dari aspek fisik dibawah ini.

1. Merupakan satuan wujud permukiman dan perumahan;

2. Ketidakteraturan bangunan dan memiliki kepadatan bangunan yang tinggi serta kondisi bangunan yang tidak memenuhi sarat;

3. Kondisi sarana dan prasarana yang tidak memenuhi syarat dapat dilihat berdasarkan aspek fisik, yang memiliki batasan sebagai berikut:

a. Jalan Lingkungan;

b. Drainase Lingkungan,

c. Penyediaan Air Bersih/Minum;

d. Pengelolaan Persampahan;

e. Pengelolaan Air Limbah;

f. Pengamanan Kebakaran; serta

g. Ruang Terbuka Publik.

Mengacu pada beberapa penyebab perkembangan permukiman kumuh menurut beberapa ahli, dapat disimpulkan penyebab perkembangan permukiman kumuh dalam 3 (tiga) faktor pemicu, yakni karena faktor ekonomi, geografi dan psikologi. 
Jurnal Planologi Vol. 16, No. 2, Oktober 2019

\section{a. Faktor Ekonomi}

Teori kebutuhan dasar manusia menurut Maslow memiliki kaitannya dengan skala prioritas kebutuhan hidup dan keutamaan dari kebutuhan perumahan dengan melihat dari kondisi ekonomi seseorang. Oleh karena itu, pada golongan masyarakat yang berpenghasilan rendah dan sangat rendah memprioritaskan faktor jarak antar lokasi rumah ke tempat kerja. Prioritas kedua yaitu faktor legalitas kepemilikan rumah dan lahan serta yang menjadi prioritas paling bawah dari faktor kualitas dan bentuk bangunan (Turner, 1982).

Beberapa literature menyimpulkan mengapa suatu permukiman menjadi permukiman kumuh dengan menghubungkan antara pertambahan penduduk dan kemiskinan yang menyebabkan lingkungan terdegradasi (Cahyadi, 2011). Menurut catatan UN-Habitat dalam Global Report on Human Settlements, permukiman kumuh ada karena: migrasi dari desa ke kota, pertumbuhan secara alami dan kombinasi dari perkembangan secara alamiah atau pindah musiman. Selain itu tumbuhnya permukiman kumuh karena mismatch supply demand pembangunan rumah dengan kebutuhan perumahan teutama untuk masyarakat berpenghasilan rendah. Harga rumah, pendapatan masyarakat dan harga substitusi merupakan unsur yang menentukan permintaan perumahan.

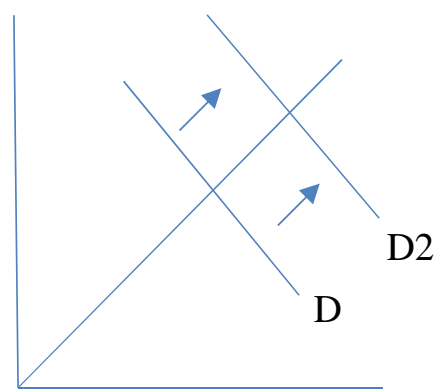

Grafik 1. Formal Housing

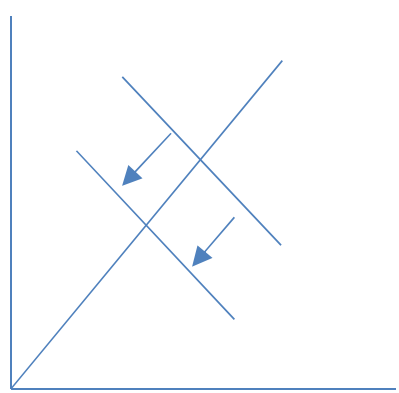

\section{Grafik 2 Slums Area}

Gambar 1.Supply demand perumahan di permukiman Sumber: Global Report on Human Settlements 2013

Supply demand perumahan di permukiman formal dan permukiman kumuh di gambarkan pada grafik diatas. Meningkatnya jumlah penduduk di pusat kota menyebabkan kebutuhan akan permukiman yang layak huni cukup tinggi. Khususnya bagi masyarakat urban yang pekerjaannya terkonsentrasi di sektor perdagangan dan jasa di pusat kota. Seperti yang digambarkan pada grafik 1, jumlah (supply) rumah layak huni terbatas sehingga harga tinggi. Masyarakat urban dari golongan ekonomi menengah ke bawah tidak mampu membeli. Dikarenakan tingginya permintaan (demand) perumahan layak huni 
(demand shifthing dari D1 ke D2) melebihi ketersediaan pasokan (supply) menyebabkan pemukiman informal dan di bawah standar banyak bermunculan karena mudah di dapat dengan biaya terjangkau. Pada grafik 2 harga permukiman informal terjangkau dengan jumlah yang tidak terbatas, sehingga masyarakat khususnya dengan low income memilih untuk tinggal di permukiman tersebut. Permukiman informal tersebut dibangun tanpa memperhatikan kualitas bahan dan jarak antar rumah. Bahkan dibangun di sebagian badan jalan, pinggir rel, pinggir kali, dan taman kota.

\section{b. Faktor Geografi}

Menurut pendapat dari Adams (1996), lokasi dan ketersediaan lahan termasuk dalam faktor geografi, dimana untuk saat ini lahan perkotaan terutama lahan perumahan semakin langka dan mahal. Peristiwa tersebut termasuk diluar keterjangkauan dari kebutuhan sebagian besar anggota masyarakat. Semakin sedikit jangkauan golongan masyarakat yang berpenghasilan rendah dalam memperoleh lahan diakibatkan oleh spekulasi lahan, kepemilikan lahan yang didominasi oleh pihak-pihak tertentu, aspek hukum kepemilikan, dan ketidakjelasan kebijaksanaan pemerintah dalam masalah lahan. Berdasarkan pernyataan diatas sehingga memunculkan fenomena mobilitas penduduk yang diawali dengan adanya gerakan centrifugal dan centripetal sehingga menyebabkan tumbuhnya permukiman kumuh di kota-kota besar khususnya di Indonesia. Colby (1933) megemukakan bahwa kemunculan dari gerakan sentrifugal dan sentripetal ini mengacu pada teori kekuatan dinamis (dinamyc forces theory).

Dalam teorinya Colby mengemukakan sebuah teori kekuatan dinamis yang mempengaruhi perubahan pemanfaatan lahan khususnya sebagai lahan pemukiman yang ada pada sebuah kota dan daerah pinggiran sekitarnya. Teori kekuatan dinamis ini menyatakan bahwa pada suatu kota dikenal ada dua macam gerakan yang sangat berperan dalam mempengaruhi kondisi pemanfaatan lahan khususnya untuk lahan permukiman, gerakan tersebut yaitu gerakan sentripetal dan gerakan sentrifugal.

Kedua gerakan tersebut terjadi karena adanya kekuatan-kekuatan sentripetal (centrypetal forces) dan kekuatan-kekuatan sentrifugal (centrifugal forces). Kekuatankekuatan sentripetal dan sentrifugal adalah merupakan kekuatan-kekuatan penarik dan pendorong. Kedua kegiatan ini mempunyai sifat yang berlawanan dan keduanya berperan secara simultan dalam menciptakan gerakan sentripetal maupun sentrifugal. Gerakan sentripetal dan gerakan setrifugal dalam teori kekuatan dinamis olen Colby ditekankan pada daerah kota yang bersifat monosentrik. Didalam teori kekuatan dinamis oleh Colby, 
diungkapkan gerakan sentripetal hanya mengacu pada daerah pusat kota sebagai area of destination dan area of interes, sedangkan daerah pinggiran kota dianggap sebagai satu kesatuan dan hanya merupakan area of origin dari gerakan sentripetal semata dan tidak pernah menjadi area of interes.

Ada beberapa kekuatan penarik utama dari gerakan sentripetal lebih terkait dengan functional force, yaitu kekuatan yang muncul sebagai akibat fungsi-fungsi ekonomi karena lokasinya berdekatan dengan konsentrasi kegiatan dan berasosiasi dengan fasilitas kegiatan ekonomi. Menurut Yunus (2001) ada tiga kegiatan penarik utama bagi pendatang luar kota, yaitu :

1. Kedekataan dengan tempat bekerja

2. Investasi

3. Kegiatan dengan fasilitas.

Hal ini sejalan pula dengan gejala yang terjadi di negara-negara yang sedang berkembang (Yunus,2001). Di daerah dekat dengan pusat kota, walaupun harga sewa lahan jauh lebih tinggi dari daerah luarnya, namun para pendatang baru dengan tingkat ekonomi rendah tetap saja cenderung bertempat tinggal dekat dengan pusat kota. Secara selintas terkesan ada pertentangan antara kemampuan ekonomi untuk sewa lahan dan tingginya harga lahan, namun sebenarnya tidak karena di sana terjadi trade off antara kenyamanan tempat tinggal dengan proksimitas ke tempat kerja. Tingginya sewa lahan dapat ditekan sedemikian rupa dengan cara dipikul bersama oleh suatu kelompok sehingga biaya tempat tinggal terasa lebih murah, namun kenyamanan dalam hal istirahat dan privasi individual terpaksa tidak dapat dinikmati.

Bermukim di permukiman kumuh merupakan suatu usaha yang dapat dijangkau dan sesuai untuk masyarakat berpenghasilan rendah dan pendapatan tidak pasti karena lokasinya sangat strategis dengan lokasi pekerjaan di perkotaan dan sumber mata pencaharian ( Turok \& Borel Saladin, 2016 ).

Tanah mempunyai nilai ekonomi. Nilai ekonomi tanah bergantung pada letak tanah. Teori Von Thunen menjelaskan bahwa tanah yang berada dekat dengan central/kota mempunyai nilai yang lebih tinggi dibandingkan letak tanah yang berada jauh dari pusat kota. Ini menjelaskan bahwa aksesibilitas dan juga biaya transportasi berpengaruh terhadap nilai tanah. Semakin tinggi biaya transportasi dan aksesibilitas yang rendah mengakibatkan tanah tersebut tidak memiliki nilai jual yang tinggi. Hal ini berpengaruh terhadap nilai tanah yang rendah. Begitu juga sebaliknya tanah yang berada dekat dengan kota, 
aksesibilitas tinggi dan biaya transportasi yang rendah berakibat pada nilai tanah tersebut yang meningkat sehingga pemilik tanah dapat mengambil harga sewa yang tinggi (Morton O’Kelly dan Deborah, 1996).

\section{c. Faktor Psikologis}

Interaksi atau hubungan antara manusia dan lingkungan alam merupakan satu kesatuan yang tidak dapat terpisahkan. Interaksi antara manusia dengan lingkungannya dapat saling menolong atau saling menguasai, Sifat dasar manusia adalah sebagai makhluk sosial, maka manusia tidak bisa terlepas berhubungan dengan manusia lainnya, sehingga muncul suatu kelompok rumah yang kemudian disebut sebagai permukiman. Kebutuhan psikis yang paling dasar adalah kebutuhan perlindungan atau rasa aman, apabila kebutuhan dasar ini dirasakan tidak dapat terpenuhi maka timbul rasa tidak betah atau tidak nyaman/aman. Kebutuhan rasa aman ini lah yang sangat menonjol pada para pemukim di permukiman kumuh, walaupun keadaan rumah yang tidak permanen sekalipun, serta keadaan lingkungan yang jauh dari syarat kesehatan, mereka tetap betah tinggal di permukiman tersebut karena adanya rasa aman, nyaman, dan saling melindungi.

\section{d. Faktor Fisik Lingkungan}

Selain ketiga faktor di atas, yang tidak kalah pentingnya disebabkan oleh faktor fisik. Istakasari, May, dkk, (2014) berpendapat bahwa penyebab kekumuhan di sekitar pusat Kota Jambi disebabkan oleh permasalahan persampahan, genangan drainase, jumlah bangunan temporer, pelayanan air minum, jarak antar bangunan yang rapat, kepemilikan tanah atau status tanah.

Menurut Wimardana (2016) berpendapat bahwa kualitas bangunan merupakan variable utama penyebab dari kekumuhan, dikarenakan pengaruh dari umur bangunan yang sudah tua sehingga tingkat kualitas bangunan ikut menurun serta dipengaruhi oleh kualitas dari material bangunan itu sendiri. Untuk variabel yang paling bawah yaitu tingkat minimnya arus migrasi suatu daerah. Hal ini diperkuat oleh tingkat ketahanan masyarakat dalam bertempat tinggal, dimana lama masyarakat tinggal yaitu lebih dari 15 tahun, dan juga ketersedaan lahan bagi masyarakat yang ingin bermigrasi untuk mendirikan bangunan baru di suatu daerah.

\subsection{Metodologi Penelitian}

Data yang digunakan dalam penelitian kali ini yaitu berupa data primer. Data primer dilakukan melalui survey langsung melalui kuesioner ke rumah tangga se-kota 
Bukittinggi dengan proporsional sampling rumah tangga yang berada di permukiman kumuh dan bukan permukiman kumuh. Adapun rumah tangga permukiman kumuh berada di 2 (dua) kelurahan diantaranya Kelurahan Aur Tajungkang Tengah Sawah (ATTS) dan Kelurahan Pakan Kurai.

Berdasarkan Riduan (2008), apabila ukuran suatu populasi diketahui maka besaran sampel dihitung dengan menggunakan rumus Taro Yamane dan Slovin, yaitu :

$$
n=\frac{N}{N^{2}+1}
$$

Keterangan:

$\mathrm{n}=$ jumlah sampel

$\mathrm{N}=$ jumlah populasi rumah tangga

$d=$ presisi, pada penelitian ini sebesar $5 \%$.

Berdasarkan rumus di atas, sehingga perhitungan total sampel dalam penelitian ini yaitu:

$\mathrm{n}=\frac{3.6}{3.6 \quad x(5 \%)+1}=395$ rumah tangga

Proporsional sampel adalah $=$ sampel yang memperhatikan dan pertimbangan unsur-unsur atau kategori di dalam suatu populasi penelitian.

$$
N_{i}=\frac{n}{N} \times N
$$

Keterangan :

$\mathrm{n}_{\mathrm{i}}=$ jumlah sampel menurut kategori

$\mathrm{N}_{\mathrm{i}}=$ jumlah populasi menurut kategori

$\mathrm{n}=$ jumlah total sampel

$\mathrm{N}=$ jumlah total populasi

Distribusi sampel Rumah Tangga sesuai dengan kategori berada di permukiman kumuh dan tidak kumuh di Kota Bukittinggi dapat dilihat pada tabel di bawah ini.

Tabel 3Distribusi Sampel Menurut Rumah Tangga di Kota Bukittinggi

\begin{tabular}{|c|l|c|c|c|}
\hline No. & \multicolumn{1}{|c|}{ Kategori Rumah Tangga } & Jumlah RT & Perhitungan & Sampel \\
\hline 1 & RT di Permukiman Kumuh & 3.618 & $\frac{3.618 \times 395}{30.688}=46,56$ & 47 \\
\hline 2 & RT Bukan di Permukiman Kumuh & 27.070 & $\frac{27.070 \times 395}{30.688}=348,43$ & 348 \\
\hline \multicolumn{2}{|c|}{ TOTAL } & 30.688 & \multicolumn{2}{|c|}{395} \\
\hline
\end{tabular}

Sumber: Bukittinggi Dalam Angka Tahun 2018 
Berdasarkan dari perhitungan di atas, maka jumlah sampel yang akan digunakan sebanyak 395 sample. Adapun Data yang digunakan pada penelitian ini adalah kualitas bangunan rumah, kepadatan bangunan rumah, pendapatan rumah tangga, pekerjaan kepala rumah tangga, pendidikan terakhir kepala keluarga, legalitas pendirian bangunan, aksesibilitas jalan, ketersediaan fasilitas kesehatan, ketersediaan fasilitas pendidikan. Pada penelitian ini unit analisisnya adalah rumah tangga yang berada di permukiman kumuh dan yang bukan berada di permukiman kumuh di Kota Bukittinggi. Adapun kelurahan yang berada di permukiman kumuh adalah Kelurahan Aur Tajungkang Tengah Sawah dan Kelurahan Pakan Kurai.

Kuesioner dirancang untuk menjawab rumusan masalah dan tujuan penelitian pada bab sebelumnya sesuai dengan standar-standar yang diatur dalam Standar Nasional Indonesia (SNI) Nomor 03-1733-2004 tentang Tata Cara Perencanaan Lingkungan Perumahan di Perkotaan dan Peraturan Menteri Pekerjaan Umum dan Perumahan Rakyat Republik Indonesia No. 02/PRT/M/2016 tentang Peningkatan Kualitas Terhadap Perumahan Kumuh dan Permukiman Kumuh.

Penelitian ini menggunakan analisis regresi logistik. Pengolahan data menggunakan software Microsoft Excel 2010 danSPSS v.16. Untuk menjawab hipotesa pada penelitian ini selanjutnya dilakukan penghitungan regresi, ditujukan untuk mengetahui pengaruh fungsional antara variabel kualitas bangunan rumah, kepadatan bangunan rumah, pendapatan rumah tangga, pekerjaan kepala rumah tangga, pendidikan terakhir kepala keluarga, legalitas pendirian bangunan, aksesibilitas jalan, ketersediaan fasilitas kesehatan, ketersediaan fasilitas pendidikan di Kota Bukittinggi. Analisis ini menggunakan analisis Logistic Regresion Model untuk menunjukkan probabilitas suatu rumah tangga di permukiman kumuh dan tidak berada di permukiman kumuh. Bentuk dari logistic distribution function model berdasarkan dari asumsi terkait variable random sehingga dapat menentukan probabilitas.

Tabel 4 Keterangan Variabel Bebas (X) dan Terikat (Y)

\begin{tabular}{|c|l|l|c|}
\hline No. & \multicolumn{1}{|c|}{ Ket. Variabel } & \multicolumn{1}{|c|}{ Value label } & Jenis Data \\
\hline 1 & $\begin{array}{l}\text { Y = Rumah Tangga se-Kota } \\
\text { Bukittinggi }\end{array}$ & $\begin{array}{l}1=\text { Kumuh } \\
0=\text { Tidak Kumuh }\end{array}$ & Kategorik \\
\hline 2 & X1 = Kualitas Bangunan Hunian & $\begin{array}{l}1=\text { Layak } \\
0=\text { Tidak Layak }\end{array}$ & Kategorik \\
\hline 3 & X2 = Kepadatan rumah. & $\begin{array}{l}1=\text { Padat } \\
0=\text { Tidak Padat }\end{array}$ & Kategorik \\
\hline 4 & X3 = Pendapatan Rumah Tangga & $\begin{array}{l}1=\text { SMK } \\
\text { Kategorik }\end{array}$ \\
\hline
\end{tabular}




\begin{tabular}{|c|l|l|c|}
\hline & & $0=>$ UMK & \\
\hline 5 & $\begin{array}{l}\text { X4 = Jenis Pekerjaan Kepala } \\
\text { Rumah Tangga }\end{array}$ & $\begin{array}{l}1=\text { Perdagangan/Jasa } \\
0=\text { Non Perdagangan/Jasa }\end{array}$ & Kategorik \\
\hline 6 & $\begin{array}{l}\text { X5 = Pendidikan terakhir Kepala } \\
\text { Rumah Tangga }\end{array}$ & $\begin{array}{l}1=\leq \text { SMP } \\
0=>\text { SMP }\end{array}$ & Kategorik \\
\hline 7 & X6 = Aksesibilitas Jalan & $\begin{array}{l}1=\text { Akses } \\
0=\text { Kurang Akses }\end{array}$ & Kategorik \\
\hline 8 & X7 = Legalitas Pendirian Bangunan & $\begin{array}{l}1=\text { Legal } \\
0=\text { Tidak Legal }\end{array}$ & Kategorik \\
\hline 9 & Xan Lahan & $\begin{array}{l}1=\text { Sedia } \\
0=\text { Tidak Sedia }\end{array}$ & Kategorik \\
& Pendidikan & $\begin{array}{l}1=\text { Sedia } \\
0=\text { Tidak Sedia }\end{array}$ & Kategorik \\
\hline 10 & X9= Ketersediaan Fasilitas & Kesehatan & \\
\hline
\end{tabular}

Sumber : Hasil Rekapitulasi 2019

\section{HASIL DAN PEMBAHASAN}

Sumber data yang digunakan adalah sumber data primer yang didapat melalui penyebaran kuesioner dan survey langsung ke 395 sampel rumah tangga se-Kota Bukittinggi, kemudian data-data hasil survey akan diolah dengan menggunakan teknik analisis regresi logistik melalui software Microsoft Excel 2010 danSPSS v.16.

a. Kualitas Bangunan

Kualitas bangunan dilihat melalui kondisi atap, dinding dan lantai. Berdasarkan dari hasil survey terlihat bahwa kualitas bangunan rumah di permukiman kumuh lebih rendah daripada rumah yang berada di bukan permukiman kumuh. Kondisi yang paling buruk banyak berada pada kondisi dinding yang rusak.Untuk lebih jelasnya dapat dilihat pada tabel di bawah ini.

Tabel 5 Kualitas Bangunan Rumah di Kota Bukittinggi Tahun 2019

\begin{tabular}{|c|c|c|c|c|c|c|c|c|c|c|}
\hline \multirow{3}{*}{$\begin{array}{l}\text { Kualitas Bangunan } \\
\text { Rumah }\end{array}$} & \multicolumn{10}{|c|}{ Jumlah Rumah Tangga } \\
\hline & \multicolumn{5}{|c|}{ Kumuh } & \multicolumn{5}{|c|}{ Tidak Kumuh } \\
\hline & Baik & $\%$ & Buruk & $\%$ & $\Sigma$ & Baik & $\%$ & Buruk & $\%$ & $\Sigma$ \\
\hline Kondisi Atap & 36 & 76,6 & 11 & 23,4 & 47 & 326 & 93,7 & 22 & 6,3 & 348 \\
\hline Kondisi Dinding & 27 & 57,4 & 20 & 42,6 & 47 & 313 & 89,9 & 35 & 10,1 & 348 \\
\hline Kondisi Lantai & 32 & 68 & 15 & 32 & 47 & 329 & 94,5 & 19 & 5,5 & 348 \\
\hline
\end{tabular}

Sumber: Hasil Kuesioner Tahun 2019 (diolah)

b. Kepadatan Bangunan

Untuk kepadatan bangunan rumah, berdasarkan hasil survey menunjukkan bahwa rumah yang berada di permukiman kumuh tidak lebih padat dari pada rumah yang berada di bukan permukiman kumuh.Hal ini disebabkan karena di permukiman kumuhterdapat migrasi penduduk yang bertempat tinggal, namun kalau dirata-ratakan kepadatan jumlah penduduk yang tinggal di permukiman kumuh berbanding luas kelurahan masing dikategorikan tinggi. 
Jurnal Planologi Vol. 16, No. 2, Oktober 2019

Tabel 6Kepadatan Bangunan Rumah di Kota Bukittinggi Tahun 2019

\begin{tabular}{|l|l|l|l|l|l|l|l|l|}
\hline \multirow{2}{*}{$\begin{array}{c}\text { Kepadatan } \\
\text { Bangunan Rumah }\end{array}$} & \multicolumn{9}{|c|}{ Kumuh } & \multicolumn{5}{c|}{ Tidak Kumuh } \\
\cline { 2 - 10 } & \multicolumn{1}{|c|}{$\Sigma$} & $\%$ & $\Sigma$ & $\%$ & $\Sigma$ & $\%$ & $\Sigma$ & $\%$ \\
\hline $\begin{array}{l}\text { Padat ( } \geq \quad 7,2 \\
\text { meter2/ jiwa) }\end{array}$ & 24 & 51 & 47 & 100 & 288 & 81,9 & 348 & 100 \\
\hline $\begin{array}{l}\text { Tidak Padat (<7,2 } \\
\text { meter2/ jiwa) }\end{array}$ & 23 & 49 & 47 & 100 & 63 & 18,1 & 348 & 100 \\
\hline
\end{tabular}

Sumber: Hasil Kuesioner Tahun 2019 (diolah)

c. Pendapatan rumah tangga.

Dilihat dari pendapatan rumah tangga menunjukkan bahwa di kawasan permukiman kumuh lebih tinggi pendapatan di atas UMK (Upah Minumum Kota) dibanding di bawah UMK (Upah Minumum Kota).Walaupun sebagian besar pendapatan rumah tangga sudah di atas UMK sedangkan tanggungan banyak/memiliki anak banyak, mereka masih dikategorikan miskin. Berdasarkan data dari jumlah rumah tangga miskin di Kota Bukittinggi menunjukkan bahwa rumah tangga miskin banyak berada di kawasan permukiman kumuh yaitu Kelurahan Aur Tajungkang Tengah Sawah (ATTS) dan Kelurahan Pakan Kurai.

Tabel 7 Kepadatan Bangunan Rumah di Kota Bukittinggi Tahun 2019

\begin{tabular}{|c|c|c|c|c|c|c|c|c|}
\hline \multirow{3}{*}{$\begin{array}{c}\text { Pendapatan Rumah } \\
\text { Tangga }\end{array}$} & \multicolumn{8}{|c|}{ Jumlah Rumah Tangga } \\
\hline & \multicolumn{4}{|c|}{ Kumuh } & \multicolumn{4}{|c|}{ Tidak Kumuh } \\
\hline & $\Sigma$ & $\%$ & $\Sigma$ & $\%$ & $\bar{\Sigma}$ & $\%$ & $\Sigma$ & $\%$ \\
\hline $\begin{array}{l}\text { Di atas UMK } \\
(\geq \text { Rp. } 2.200 .000,-)\end{array}$ & 25 & 53,2 & 47 & 100 & 242 & 69,6 & 348 & 100 \\
\hline $\begin{array}{l}\text { Di bawah UMK } \\
(<\text { Rp. } 2.200 .000,-)\end{array}$ & 22 & 46,8 & 47 & 100 & 106 & 30,4 & 348 & 100 \\
\hline
\end{tabular}

Sumber: Hasil Kuesioner Tahun 2019 (diolah)

d. Pekerjaan kepala rumah tangga.

Pekerjaan kepala rumah tangga masih di dominasi dari sektor perdagangan.Sebagian besar dari mereka merupakan pegawai toko yang rata-rata di gaji Rp.50.000 s/d Rp. 100.000 per harinya. Untuk lebih jelasnya dapat dilihat pada tabel di bawah ini:

Tabel 8 Pekerjaan Kepala Rumah Tangga di Kota Bukittinggi Tahun 2019

\begin{tabular}{|c|c|c|c|c|}
\hline \multirow{3}{*}{ Pekerjaan Kepala Rumah Tangga } & \multicolumn{4}{|c|}{ Jumlah Rumah Tangga } \\
\hline & \multicolumn{2}{|r|}{ Kumuh } & \multicolumn{2}{|c|}{ Tidak Kumuh } \\
\hline & $\Sigma$ & $\%$ & $\Sigma$ & $\%$ \\
\hline $\begin{array}{l}\text { Pertanian, perkebunan, kehutanan, } \\
\text { peternakan }\end{array}$ & 1 & 2,1 & 13 & 3,7 \\
\hline Keuangan dan asuransi & - & - & 4 & 1,1 \\
\hline Industri/ pabrik & - & - & 9 & 2,6 \\
\hline $\begin{array}{l}\text { Transportasi, pergudangan, } \\
\text { informasi, dan komunikasi }\end{array}$ & 7 & 14,9 & 11 & 3,2 \\
\hline Konstruksi/ bangunan & 1 & 2,1 & 17 & 4,9 \\
\hline
\end{tabular}

Wilko Rahmad Zulkarnaini, Elfindri, Delfia Tanjung Saril180 Faktor-Faktor Yang Mempengaruhi Rumah Tangga Dalam Perkembangan Permukiman Kumuh... 
Jurnal Planologi Vol. 16, No. 2, Oktober 2019

Available : http://jurnal.unissula.ac.id/index.php/psa

\begin{tabular}{|c|c|c|c|c|}
\hline \multirow{3}{*}{ Pekerjaan Kepala Rumah Tangga } & \multicolumn{4}{|c|}{ Jumlah Rumah Tangga } \\
\hline & \multicolumn{2}{|r|}{ Kumuh } & \multicolumn{2}{|c|}{ Tidak Kumuh } \\
\hline & $\Sigma$ & $\%$ & $\Sigma$ & $\%$ \\
\hline Perdagangan & 23 & 48,9 & 193 & 55,5 \\
\hline Jasa & 10 & 21,4 & 41 & 11,8 \\
\hline Pegawai Pemerintah & 5 & 10,6 & 60 & 17,2 \\
\hline TOTAL & 47 & 100 & 348 & 100 \\
\hline
\end{tabular}

Sumber: Hasil Kuesioner Tahun 2019

e. Pendidikan terakhir kepala rumah tangga.

Sebagian besar pendidikan terakhir kepala rumah tangga di permukiman kumuh adalah tamatan SD, sehingga kurang memiliki pengetahuan tentang rumah yang layak huni dan lingkungan yang bersih dan sehat. Untuk lebih jelasnya dapat dilihat pada tabel di bawah ini.

Tabel 9 Pendidikan Terakhir Kepala Rumah Tangga di Kota Bukittinggi Tahun 2019

\begin{tabular}{|c|c|c|c|c|}
\hline \multirow{3}{*}{$\begin{array}{c}\text { Pendidikan Terakhir } \\
\text { Kepala RT }\end{array}$} & \multicolumn{4}{|c|}{ Jumlah Rumah Tangga } \\
\hline & \multicolumn{2}{|c|}{ Kumuh } & \multicolumn{2}{|c|}{ Tidak Kumuh } \\
\hline & $\Sigma$ & $\%$ & $\Sigma$ & $\%$ \\
\hline SD & 18 & 38,3 & 35 & 10,1 \\
\hline SMP & 13 & 27,7 & 118 & 33,9 \\
\hline SMA & 11 & 23,4 & 119 & 34,2 \\
\hline Diploma & 3 & 6,4 & 43 & 12,3 \\
\hline Sarjana & 2 & 4,2 & 33 & 9,5 \\
\hline TOTAL & 47 & 100 & 348 & 100 \\
\hline
\end{tabular}

Sumber: Hasil Kuesioner Tahun 2019 (diolah)

f. Aksesibilitas jalan

Sebagian besar jalan-jalan di rumah tangga permukiman kumuh tidak menghadap jalan dengan lebar badan jalan minimal 1.5 meter yang permukannya tidak diperkeras dan rusak.Untuk lebih jelasnya dapat dilihat pada tabel di bawah ini.

Tabel 10Aksesibilitas Jalan Rumah Tangga di Kota Bukittinggi Tahun 2019

\begin{tabular}{|c|c|c|c|c|c|c|c|c|c|c|}
\hline \multirow{3}{*}{ Aksesibilitas Jalan } & \multicolumn{10}{|c|}{ Jumlah Rumah Tangga } \\
\hline & \multicolumn{5}{|c|}{ Kumuh } & \multicolumn{5}{|c|}{ Tidak Kumuh } \\
\hline & $\mathrm{Ya}$ & $\%$ & Tidak & $\%$ & $\Sigma$ & Ya & $\%$ & Tidak & $\%$ & $\Sigma$ \\
\hline $\begin{array}{l}\text { AKSES LANGSUNG ke } \\
\text { jalan yang mempunyai } \\
\text { lebar badan jalan minimal } \\
1.5 \text { meter dan tidak } \\
\text { terhalang oleh bangunan } \\
\text { lain }\end{array}$ & 28 & 59,6 & 19 & 40,4 & 47 & 260 & 74,7 & 88 & 25,3 & 348 \\
\hline $\begin{array}{l}\text { POSISI MUKA bangunan } \\
\text { hunian menghadap jalan } \\
\text { dengan lebar badan jalan } \\
\text { minimal } 1.5 \text { meter }\end{array}$ & 29 & 61,7 & 18 & 38,3 & 47 & 262 & 75,3 & 86 & 24,7 & 348 \\
\hline $\begin{array}{l}\text { POSISI MUKA bangunan } \\
\text { hunian menghadap jalan } \\
\text { dengan lebar badan jalan } \\
\text { minimal } 1.5 \text { meter yang } \\
\text { permukannya diperkeras } \\
\text { dan tidak rusak }\end{array}$ & 18 & 38,3 & 29 & 61,7 & 47 & 243 & 69,8 & 105 & 30,2 & 348 \\
\hline
\end{tabular}

Sumber: Hasil Kuesioner Tahun 2019 (diolah) 
Jurnal Planologi Vol. 16, No. 2, Oktober 2019

g. Legalitas pendirian lahan dan bangunan.

Sebagian besar rumah di permukiman kumuh memiliki Izin Mendirikan Bangunan (IMB) dan memiliki surat yang diakui negara. Hasil ini disebabkan karena peruntukkannya berdasarkan Rencana Tata Ruang Wilayah (RTRW) memang sebagai kawasan permukiman, namun setelah keluar IMB beberapa tahun kemudian ditambahkan bangunan ke depan/ke belakang/ke samping/ke atas tanpa sepengetahuan dan seizin dari Pemerintah Kota Bukittinggi. Hal ini berarti masih rendahnya pengawasan pemerintah terhadap bangunan rumah di Kota Bukittinggi.

Tabel 11.Legalitas Bangunan dan Lahan PadaRumah Tangga di Kota Bukittinggi Tahun 2019

\begin{tabular}{|c|c|c|c|}
\hline \multicolumn{2}{|c|}{ Legalitas Bangunan dan Lahan } & $\Sigma \mathrm{RT}$ & $\%$ \\
\hline \multirow[t]{6}{*}{ Kumuh } & Memiliki IMB & 30 & 63,8 \\
\hline & Tidak Memiliki IMB & 17 & 36,2 \\
\hline & TOTAL & 47 & 100 \\
\hline & Memiliki Surat Negara & 32 & 68 \\
\hline & Tidak Memiliki Surat Negara & 15 & 32 \\
\hline & TOTAL & 47 & 100 \\
\hline \multirow[t]{6}{*}{ Tidak Kumuh } & Memiliki IMB & 233 & 67 \\
\hline & Tidak Memiliki IMB & 115 & 33 \\
\hline & TOTAL & 348 & 100 \\
\hline & Memiliki Surat Negara & 244 & 70,1 \\
\hline & Tidak Memiliki Surat Negara & 104 & 29,9 \\
\hline & TOTAL & 348 & 100 \\
\hline
\end{tabular}

Sumber: Hasil Kuesioner Tahun 2019 (diolah)

h. Ketersediaan fasilitas pendidikan

Untuk menyukseskan wajib belajar 9 (sembilan) tahun, sebagian besar anggota rumah tangga di permukiman kumuh sudah bersekolah di kelurahan/kecamatan yang sama. Penjelasan dari pernyataan diatas dapat dilihat pada tabel dibawah ini.

Tabel 12 Ketersediaan Fasilitas Pendidikan pada Rumah Tangga di Kota Bukittinggi

Tahun 2019

\begin{tabular}{|c|c|c|c|}
\hline \multicolumn{2}{|r|}{ Ketersediaan Fasilitas Pendidikan } & $\Sigma \mathrm{RT}$ & $\%$ \\
\hline \multirow[t]{6}{*}{ Kumuh } & kelurahan/ kecamatan yang sama & 26 & 55,3 \\
\hline & di luar kecamatan & 7 & 14,9 \\
\hline & di kota lain & 2 & 4,3 \\
\hline & Tidak sekolah & 2 & 4,3 \\
\hline & tidak ada anggota rumah tangga usia wajib belajar & 10 & 21,2 \\
\hline & TOTAL & 47 & 100 \\
\hline \multirow{6}{*}{$\begin{array}{l}\text { Tidak } \\
\text { Kumuh }\end{array}$} & kelurahan/ kecamatan yang sama & 176 & 50,6 \\
\hline & di luar kecamatan & 35 & 10,1 \\
\hline & di kota lain & 7 & 2 \\
\hline & Tidak sekolah & 4 & 1,1 \\
\hline & tidak ada anggota rumah tangga usia wajib belajar & 126 & 36,2 \\
\hline & TOTAL & 348 & 100 \\
\hline
\end{tabular}

Sumber: Hasil Kuesioner Tahun 2019 (diolah) 
Jurnal Planologi Vol. 16, No. 2, Oktober 2019

i. Ketersediaan fasilitas kesehatan

Pada permukiman kumuh terdapat sebagian besar rumah tangga yang memanfaatkan fasilitas kesehatan yang berada di kelurahan/ kecamatan yang sama. Penjelasan dari pernyataan diatas dapat dilihat pada tabel dibawah ini.

Tabel 13 Ketersediaan Fasilitas Kesehatan pada Rumah Tangga di Kota Bukittinggi Tahun 2019

\begin{tabular}{|c|c|c|c|}
\hline \multicolumn{2}{|r|}{ Ketersediaan Fasilitas Kesehatan } & $\boldsymbol{\Sigma} \mathbf{R T}$ & $\%$ \\
\hline \multirow[t]{5}{*}{ Kumuh } & di lingkungan RT & 15 & 31,9 \\
\hline & di kelurahan/ kecamatan yang sama & 25 & 53,2 \\
\hline & di luar kecamatan & 7 & 14,9 \\
\hline & di kota lain & - & - \\
\hline & TOTAL & 47 & 100 \\
\hline \multirow{5}{*}{$\begin{array}{l}\text { Tidak } \\
\text { Kumuh }\end{array}$} & di lingkungan RT & 47 & 13,5 \\
\hline & di kelurahan/ kecamatan yang sama & 217 & 62,4 \\
\hline & di luar kecamatan & 83 & 23,9 \\
\hline & di kota lain & 1 & 0,2 \\
\hline & TOTAL & 348 & 100 \\
\hline
\end{tabular}

Sumber: Hasil Kuesioner Tahun 2019 (diolah)

Data dari distribusi kuesioner diolah dengan analisis regresi logistik. variabel bebas (X) dan terikat (Y) dapat dilihat pada bagian metodologi di atas. Hasil berikut adalah data yang diproses:

Tabel 14. Hasil Uji Overall Fit Test Model Pemukiman Kumuh di Kota Bukittinggi Tahun 2019

\begin{tabular}{|c|c|c|c|c|}
\hline \multicolumn{5}{|c|}{ Omnibus Tests of Model Coefficients } \\
\hline 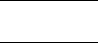 & 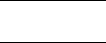 & Chi-square & $\mathrm{df}$ & Sig. \\
\hline \multirow[t]{3}{*}{ Step 1} & Step & 56.312 & 9 & 0.000 \\
\hline & Block & 56.312 & 9 & 0.000 \\
\hline & Model & 56.312 & 9 & 0.000 \\
\hline
\end{tabular}

Sumber : Hasil Survey dan Olahan SPSS 2019

Rumus yang digunakan untuk menentukan kelayakan model yaitu memaikai statistik uji nisbah kemungkinan (likelihood ratio test), yaitu statistik uji G. Maka hipotesis yang digunakan dalam pengujian kali ini yaitu:

$\mathrm{H}_{0}: \beta_{I}=\beta_{l}=\ldots=\beta_{k}=0$ (tidak ada pengaruh semua variabel independen terhadap variabel dependen)

$\mathrm{H}_{1}$ : paling tidak terdapat satu $\beta_{j} \neq 0$ untukj $=1,2,3, \ldots, \mathrm{k}$ (ada pengaruh variabel independen terhadap variabel dependen)

Tolak $\mathrm{H}_{0}$ jika nilai sig $<0.05$.

Berdasarkan output omnibus test terlihat bahwa signifikansi model $0.000<0.05$ yang artinya bahwa secara umum model signifikan secara statistik.

Keputusan: Tolak $\mathrm{H}_{0}$ 
Kesimpulan: Terlihat nilai $\mathrm{G}^{2}$ sebesar 56.312 dengan $p$-value 0.000 (model) artinya bahwaberdasarkan tingkat kepercayaan $95 \%$ ada minimal satu variabel bebas yang berpengaruh pada variabel terikat. Jadi kesimpulannya bahwa model layak sehingga dapat digunakan untuk analisis selanjutnya.

Kemudian digunakan uji kecocokan model (goodness of fit) dari Hosmer and Lemeshow.Pengujian kali ini digunakan untuk melihat apakah terdapat kecocokan antara model dengan data untuk menjelaskan hubungan antar variabel. Kecocokan model dapat dilihat dari uji hipotesis sebagai berikut

$\mathrm{H}_{0}$ : Model telah cukup mampu menjelaskan data/sesuai

$\mathrm{H}_{1}$ : Model tidak cukup mampu menjelaskan data

Tolak $\mathrm{H}_{0}$ jika signifikansi value Chi-Square uji Hosmer and Lemeshow $<0.05$

Tabel 7 Uji Kecocokan Model (Goodness of Fit) Model Permukiman Kumuh di Kota Bukittinggi Tahun 2019

\begin{tabular}{|c|c|c|c|}
\hline \multicolumn{4}{|c|}{ Hosmer and Lemeshow Test } \\
\hline Step & Chi-square & $\mathrm{df}$ & Sig. \\
\hline 1 & 5.229 & 8 & 0.733 \\
\hline
\end{tabular}

Sumber : Hasil Survey dan Olahan SPSS 2019

Terlihat pada tabel di atas bahwa signifikan value $=0.733>0.05$.

Keputusan: terima $\mathrm{H}_{0}$

Jadi kesimpulan hasil diatas adalah bahwa dari tingkat keyakinan 95\% berarti kemampuan penjelasan data/cocok yaitu dengan menggunakan model regesi logistik, sehingga model ini memiliki tingkat kelayakan yang tinggi untuk digunakan dalam tahapan analisis berikutnya dikarenakan tidak muncul perdedaan secara nyata anatara klasifikasi yang diamati dan yang telah diprediksi.

Tabel 8 Hasil Estimasi Koefisien Model, Nilai Uji Wald, Signifikansi, dan Nilai Odds Ratio dari Regresi Logistik Model Permukiman Kumuh di Kota Bukittinggi Tahun 2019

\begin{tabular}{|l|l|l|l|l|l|l|l|}
\hline \multicolumn{2}{|c|}{} & B & S.E. & Wald & df & Sig. & Odds Ratio \\
\hline \multirow{3}{*}{ Step $1^{\text {a }}$} & X1.Kualitas_Hunian & -1.264 & 0.398 & 10.068 & 1 & 0.002 & 0.282 \\
\cline { 2 - 8 } & X2.Kepadatan_Bangunan & -1.195 & 0.380 & 9.889 & 1 & 0.002 & 0.303 \\
\cline { 2 - 8 } & X3.Pendapatan & -0.085 & 0.417 & 0.041 & 1 & 0.839 & 0.919 \\
\cline { 2 - 8 } & X4.Pekerjaan_Kepala_RT & 0.058 & 0.380 & 0.023 & 1 & 0.878 & 1.060 \\
\cline { 2 - 8 } & X5.Pendidikan & -1.044 & 0.455 & 5.257 & 1 & 0.022 & 0.352 \\
\hline & X6.Aksesibilitas_Jalan & -1.044 & 0.352 & 8.780 & 1 & 0.003 & 0.352 \\
\hline & $\begin{array}{l}\text { X7.Legalitas_Pendirian_Ban } \\
\text { gunan }\end{array}$ & 0.740 & 0.397 & 3.471 & 1 & 0.062 & 2.096 \\
\cline { 2 - 8 } & X8.Fasilitas_Pendidikan & -0.888 & 0.453 & 3.845 & 1 & 0.050 & 0.412 \\
\cline { 2 - 8 } & X9.Fasilitas_Kesehatan & 0.169 & 0.494 & 0.117 & 1 & 0.732 & 1.184 \\
\cline { 2 - 8 } & Constant & 1.335 & 0.832 & 2.572 & 1 & 0.109 & 3.799 \\
\hline
\end{tabular}

Sumber : Hasil Survey dan Olahan SPSS 2019 
Jurnal Planologi Vol. 16, No. 2, Oktober 2019

Dalam model Regresi logistik, interpretasi parameter menggunakan nilai odds ratio (perbandingan risiko) atau dalam adjusted probability (probabilitas yang disesuaikan). Pada tabel di atas, nilai odds ratio dapat dilihat pada kolom $\operatorname{Exp}(\mathrm{B})$. Hasil output model regresi logistik rumah tangga permukiman kumuh di Kota Bukittinggi dapat ditulis dalam bentuk struktur sebagai berikut:

\section{Logit $Y=1.335-1.264 X 1-1.195 X 2-0.085 X 3+0.058 X 4-1.044 X 5-1.044 X 6+0.740 X 7-$ $0.888 \times 8+0.169 \times 9$}

Faktor-faktor yang membawa pengaruh tumbuhnya permukiman kumuh di Kota Bukittinggi yaitu Kualitas Hunian, Kepadatan Bangunan, Pendidikan, Aksesibilitas jalan.Sementara faktor-faktor lainnya yaitu pendapatan rumah tangga, legalitas bangunan, fasilitas pendidikan jenis pekerjaan kepala rumah tangga dan fasilitas kesehatan tidak berpengaruh.

Kualitas hunian mempengaruhi perkembangan permukiman kumuh di Kota Bukittinggi, dengan sig. 0,002<0,05 pada tingkat signifikansi $5 \%$. Nilai odds ratio 0,282 berarti bahwa jika kualitas hunian rumah yang layak, peluang untuk daerah kumuh adalah 0,282 kali dibandingkan dengan rumah tangga yang bukan di kawasan kumuh, dapat disimpulkan bahwa kualitas hunian rumah di permukiman kumuh tidak layak. ini dibuktikan dengan kondisi lapangan yang menunjukkan bahwa lebih banyak permukiman kumuh terjadi kondisi atap bocor, dinding dan lantai yang rusak maupun yang masih tanah.

Kepadatan bangunan memengaruhi lokasi pemukiman dengan sig. 0,002<0,05 pada tingkat signifikansi 5\%. Nilai odds ratio 0,303 berarti bahwa jika kepadatan bangunan padat ( $\geq 7.2$ meter $^{2}$ / orang) maka peluang permukiman kumuh adalah 0,303 kali dibandingkan dengan bukan di permukiman kumuh, dapat disimpulkan bahwa bukan di permukiman kumuh cenderung padat kepadatan bangunan ( $\geq 7,2 \mathrm{~m} 2$ / orang) dibandingkan dengan daerah kumuh. Ini menunjukkan bahwa mayoritas penghuni rumah tangga di daerah bukan di permukiman kumuh lebih padat, karena kepadatan bangunan rumah ratarata $\geq 7,2 \mathrm{~m} 2$ / orang.

Pendidikan terakhir kepala keluarga memengaruhi tempat pemukiman dengan sig. $0,022<0,05$ pada tingkat signifikansi $5 \%$. Nilai odds ratio 0,352 berarti bahwa jika pendidikan $\geq$ sekolah menengah pertama, peluang untuk daerah kumuh adalah 0,352 kali dibandingkan dengan bukan di permukiman kumuh, kesimpulannya bahwa rumah tangga bukan di permukiman kumuh cenderung memiliki pendidikan yang lebih tinggi 
dibandingkan dengan daerah kumuh. ini berarti bahwa tingkat pendidikan mempengaruhi penentuan unuk tinggal atau menetap pada permukiman kumuh di Kota Bukittinggi.

Aksesibilitas Jalan memengaruhi lokasi pemukiman dengan sig. 0,003 $<0,05$ pada tingkat signifikansi 5\%. Nilai odds ratio 0,352 berarti bahwa jika Anda memiliki aksesibilitas jalan yang baik maka peluang permukiman kumuh adalah 0,352 kali dibandingkan dengan bukan permukiman kumuh, dapat disimpulkan bahwa rumah tangga bukan di permukiman kumuh cenderung memiliki aksesibilitas jalan yang baik dibandingkan dengan permukiman kumuh. Ini dibuktikan dengan kondisi jalan di kawasan permukiman kumuh yang memiliki kurang memiliki akses langsung ke jalan, tidak memiliki lebar minimum 1,5 meter badan jalan dan terhalang oleh bangunan lain. selain itu, banyak yang rusak dan masih tanah, menyebabkan genangan air saat hujan.

\section{KESIMPULAN DAN SARAN}

\subsection{Kesimpulan}

Dari pembahasan di atas, maka faktor-faktor yang mempengaruhi permukiman kumuh di Kota Bukittinggi yaitu kualitas hunian, kepadatan bangunan, pendidikan terakhir kepala rumah tangga, dan aksesibilitas jalan. Sementara untuk karakteristik pendapatan, pekerjaan kepala rumah tangga, legalitas lahan dan bangunan dan fasilitas pendidikan dan kesehatan tidak berpengaruh.

Dengan penyusunan program kebijakan permukiman yang berfokus kepada kualitas hunian, kepadatan bangunan, pendidikan terakhir kepala rumah tangga dan aksesibilitas jalan. Program kebijakan dapat berupa :

a. Program Bedah Rumah

b. Program Pembangunan Rumah, seperti rusunawa dan rumah subsidi.

c. Program wajib belajar 9 tahun melalui Paket A/B/C.

d. Program pembangunan jalan baru atau rehabilitasi jalan.

Keempat program kebijakan di atas, diharapkan dapat menanggulangi permukiman kumuh di Kota Bukittinggi, sehingga kota yang sehat, indah dan bersih serta berkelanjutan dapat terwujud.

\subsection{Saran}

Berdasarkan dari kesimpulan di atas, maka dapat disarankan sebagai berikut:

1. Perlu adanya sosialisasi program kepada masyarakat terkait program bedah rumah, pembangunan rumah sewa atau rumah subsidi, program wajib belajar 9 (sembilan) tahun, dan pembangunan jalan/rehabilitasi jalan.

Wilko Rahmad Zulkarnaini, Elfindri, Delfia Tanjung Saril186 Faktor-Faktor Yang Mempengaruhi Rumah Tangga Dalam Perkembangan Permukiman Kumuh... 
Jurnal Planologi Vol. 16, No. 2, Oktober 2019

Available : http://jurnal.unissula.ac.id/index.php/psa

2. Pemerintah daerah di dalam pelaksanaan program-program tersebut harus memenuhi standar perumahan, pendidikan dan jalan dengan berpihak kepada warga miskin di permukiman kumuh. Salah satu caranya yaitu dengan memanfaatkan dana Coorporate Social Responsibility (CSR) dari perusahaan maupun sektor perbankan, sehingga penggunaan dana pemerintah dapat diminimalisir.

3. Perlu adanya kerja sama dengan komitmen yang tinggi antara pihak pemerintah kota (legislative, eksekutif) dan masyarakat agar dapat terangkum dalam dokumen perencanaan daerah, seperti Rencana Pembangunan Jangka Panjang (RPJP), Rencana Pembangunan Jangka Menengah (RPJM), Rencana Strategis (Renstra) Organisasi Perangkat Daerah (OPD) dan Rencana Kerja setiap tahunnya. Hal terpenting adalah perencanaan yang ditetapkan tersebut harus konsisten dengan pelaksanaan anggaran setiap tahunnya, sehingga kawasan permukiman kumuh di Kota Bukittinggi dapat diatasi secara terintegrasi dan berkelanjutan.

\section{DAFTAR PUSTAKA}

Adams. (1999). ISO 14001. “a Key Ingredient Of Competitive Edge. Env”.Law Mgmt.

Almanac, U. H. S. (2015). 2016. Tracking Improvement in the Lives of Slum Dwellers. Technical Report.

Cahyadi,dkk.(2011). Relasi Kemiskinan dan Degradasi Lingkungan: Bentuk dan Konteksnya dalam Lingkup Perkotaan: LIPI.

Colby, C. C. (1933). Centrifugal and centripetal forces in urban geography. Annals of the Association of American Geographers, 23(1), 1-20.

Un-Habitat. (2013). Planning and design for sustainable urban mobility: Global report on human settlements 2013. Taylor \& Francis.

Istikasari, M., \& Khadiyanto, P. (2014). Identifikasi Permukiman Kumuh di Pusat Kota Jambi. Ruang, 2(4), 301-310.

Marx, B., Stoker, T., \& Suri, T. (2013).The economics of slums in the developing world. Journal of Economic Perspectives, 27(4), 187-210.

O'Kelly, M., \& Bryan, D. (1996). Agricultural location theory: von Thunen's contribution to economic geography. Progress in Human Geography, 20(4), 457-475.

Peraturan Presiden Negara Republik Indonesia No. 2 Tahun 2015 Tentang Rencana Pembangunan Jangka Menengah Nasional Tahun 2015 - 2019.

Wilko Rahmad Zulkarnaini, Elfindri, Delfia Tanjung Saril187 Faktor-Faktor Yang Mempengaruhi Rumah Tangga Dalam Perkembangan Permukiman Kumuh... 
Jurnal Planologi Vol. 16, No. 2, Oktober 2019

Peraturan Menteri Pekerjaan Umum dan Perumahan Rakyat Republik Indonesia No. 02/PRT/M/2016 tentang Peningkatan Kualitas Terhadap Perumahan Kumuh dan Permukiman Kumuh.

Riduan.(2008). Dasar-Dasar Statistika.Bandung : Alfabeta.

Standar Nasional Indonesia (SNI) Nomor 03-1733-2004. Tata Cara Perencanaan Lingkungan Perumahan di Perkotaan. Jakarta:Badan Standarisasi Nasional.

Turok, I., \& Borel-Saladin, J. (2016). Backyard shacks, informality and the urban housing crisis in South Africa: stopgap or prototype solution?.Housing Studies, 31(4), 384409.

Turner.J.F.C,(1982).Housing Issues and The Standard Problems, In Ekistics.Vol. 33 No. 196. pp. $152-158$.

Turner, J.F.C.(1982). Housing By People, Towards Autonomy in Building Environment.London : Morions Boyars Publisher Ltd.

Undang-undang Negara Republik Indonesia No. 1 Tahun 2011 Tentang Perumahan dan Kawasan Permukiman.

Wimardana, A. S. (2016). Faktor Prioritas Penyebab Kumuh Kawasan Permukiman Kumuh Di Kelurahan Belitung Selatan Kota Banjarmasin. Jurnal Teknik ITS, 5(2), C166-C171.

Yunus, H. S. (2001). Perubahan Pemanfaatan Lahan Di Daerah Pinggir Kota Kasus di Pinggiran Kota Yogyakarta, Disertasi, Universitas Gadjah Mada, Yogyakarta. 